\title{
Syringocystadenoma Papilliferum of the Back Combined with a Tubular Apocrine Adenoma
}

\author{
Hyun Joo Lee, M.D., Eujin Cho, M.D., Min Ho Kim, M.D., Sang Hyun Cho, M.D., \\ Jeong Deuk Lee, M.D. \\ Department of Dermatology, Incheon St. Mary's Hospital, College of Medicine, The Catholic University of Korea, Incheon, Korea
}

Syringocystadenoma papilliferum (SCAP) and tubular apocrine adenoma (TAA) are rare benign sweat gland tumors. SCAP and TAA may have a histopathologic overlap, but few cases of a SCAP combined with a TAA have been reported. Herein we describe an unusual case of a SCAP co-existing with a TAA located on the back of a 12-year-old girl. (Ann Dermatol 23(S2) S151 S154, 2011)

\section{-Keywords-}

Back, Syringocystadenoma papilliferum, Tubular apocrine adenoma

\section{INTRODUCTION}

Syringocystadenoma papilliferum (SCAP) and tubular apocrine adenoma (TAA) are rare, benign, sweat gland tumors. In some cases, TAAs can arise in association with SCAPs, and SCAPs are often situated in the superficial portion of TAAs ${ }^{1-11}$. In a few cases of TAAs associated with SCAPs, pre-existing sebaceous nevi have been described $^{1-6,8,9}$. Herein, we describe an unusual case of a SCAP accompanied by a TAA without a sebaceous nevus on the back of a 12-year-old girl.

Received October 7, 2010, Revised December 10, 2010, Accepted for publication December 30, 2010

Corresponding author: Jeong Deuk Lee, M.D., Department of Dermatology, Incheon St. Mary's Hospital, College of Medicine, The Catholic University of Korea, 665 Bupyeong-dong, Bupyeong-gu, Incheon 403-720, Korea. Tel: 82-32-280-5102, Fax: 82-32-506-9514, E-mail: leejd@olmh.cuk.ac.kr

This is an Open Access article distributed under the terms of the Creative Commons Attribution Non-Commercial License (http:// creativecommons.org/licenses/by-nc/3.0) which permits unrestricted non-commercial use, distribution, and reproduction in any medium, provided the original work is properly cited.

\section{CASE REPORT}

A 12-year-old girl presented with multiple confluent erythematous papules forming a eroded plaque on the left lower back that had been present since birth. The lesion slowly enlarged with time. The patient had no other significant skin lesions, and the medical and family histories were unremarkable. On cutaneous examination, a $1.8 \times 2.5 \mathrm{~cm}$, well-defined, erythematous eroded plaque was situated on the left side of the lower back with a papillomatous surface and a rubbery consistency (Fig. 1). An excisional biopsy was performed (Fig. 2A). On the histopathologic examination, the overlying epidermis showed hyperkeratosis, acanthosis, and papillomatosis. The upper part of the lesion showed cystic and irregularly dilated tubular structures with deep invaginations, from which emerged thick papillomatous projections lined with two rows of epithelial cells. The luminal raw of cells

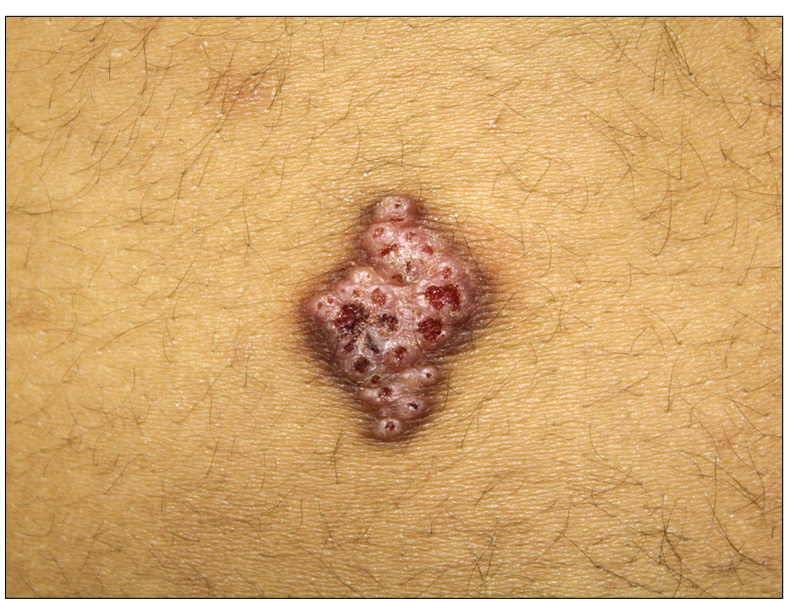

Fig. 1. An erythematous well-defined and papillomatous plaque with superficial erosion and crust on the left side of the lower back. 


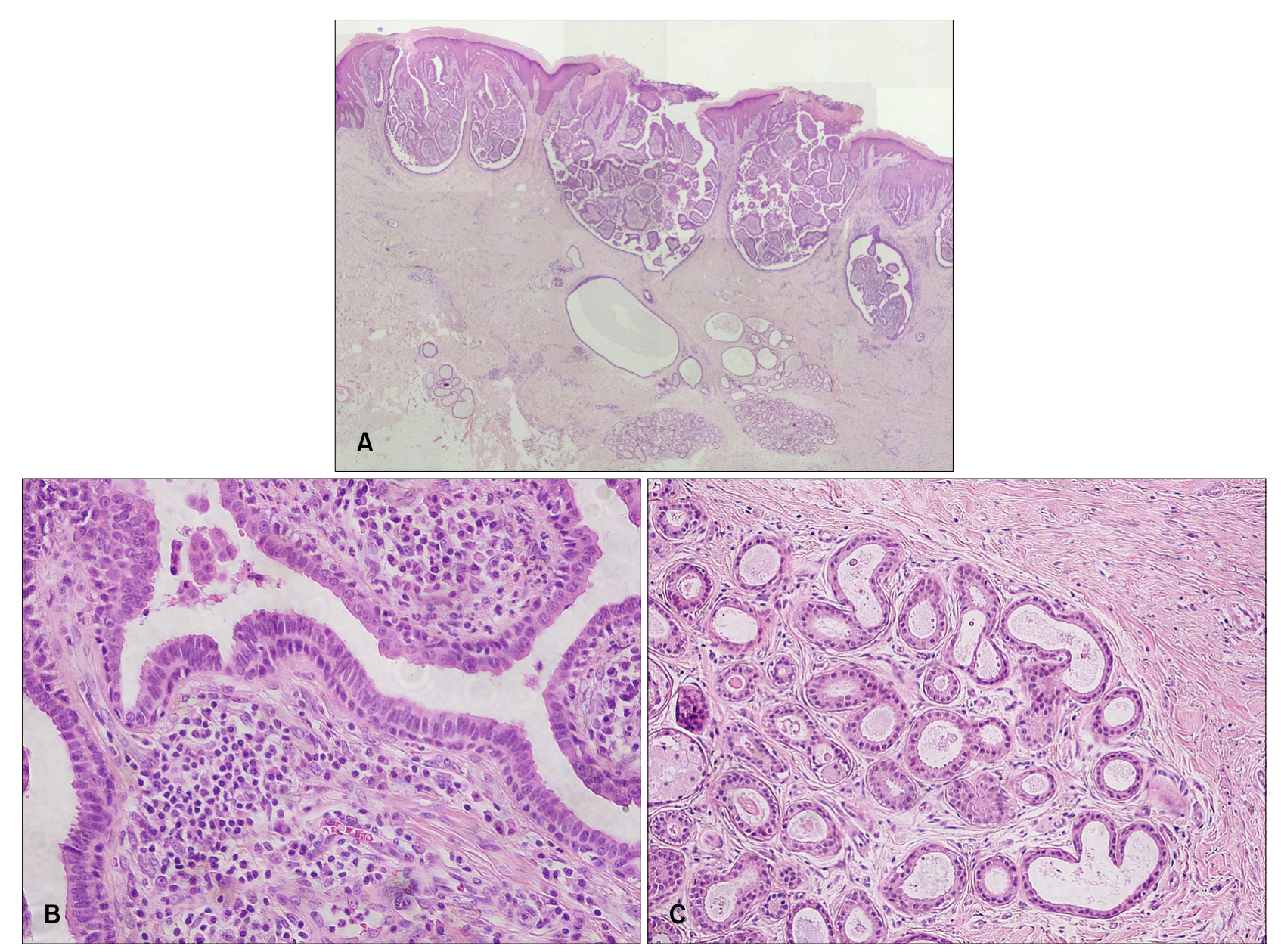

Fig. 2. Views of the tumor. (A) The upper portion of the tumor had a cystic invagination that extends downward from the epidermis, and the lower portion exhibited islands of irregular-shaped tubular structures in the deep dermis at the excision specimen (H\&E, $\times 20$ ). (B) Two different epithelial cell layers lining the invaginated area and papillary projections in the upper portion of tumor. The luminal row consisted of high columnar cells showing active decapitation secretion, and the outer row consisted of small cuboidal cells. There was stromal infiltration of many plasma cells $(\mathrm{H} \& \mathrm{E}, \times 400)$. (C) The numerous cystic and branching tubular structures in the dermis surrounded by a paucicellular fibrous stroma. The tubular structures have a dual or multilayered epithelium and the luminal cells showing evidence of active decapitation secretion in the dermis $(\mathrm{H} \& \mathrm{E}, \times 100)$.

consisted of columnar cells with oval nuclei and faintly eosinophilic cytoplasm. The outer row of cells consisted of small cuboidal cells with round nuclei and scanty cytoplasm. Plasma cells infiltrated the stroma (Fig. 2B). The deeper part of the specimen exhibited tubular structures of variable sizes. The numerous cystic and branching tubular structures in the dermis were surrounded by a paucicellular fibrous stroma. The peripheral layer of tubular structures consisted of flattened cuboidal cells, and the luminar layer was composed of cuboidal cells. Irregular-shaped tubules have a dual or multilayered epithelium with the peripheral layer representing myoepithelial cells. The cells lining the lumina showed evidence of active decapitation secretion (Fig. 2C). After total excision, no recurrence was noted in the following 4 months.

\section{DISCUSSION}

A SCAP is an uncommon benign sweat gland tumor that is usually first noted at birth or in early childhood and presents as a solitary papule, several papules in a linear arrangement, or as a plaque. The lesion increases in size at puberty, becoming papillomatous and often crusted. A SCAP occurs most commonly on the scalp and face, but in $25 \%$ of the cases, it occurs elsewhere (e.g., trunk, upper arms, vulva, and thighs) ${ }^{12}$. Histopathologically, a SCAP consists of a cystic and papillary growth of epithelial elements projecting downward into the dermis and opening onto the skin surface through one or more orifices. Usually the tumor consists of two layers of epithelial cells: the peripheral layer is cuboidal and the inner, columnar cell layer shows evidence of decapitation 
secretion. The connective tissue stroma of the papillomatous projections is marked by rich infiltration of inflammatory cells; most notably there is a large number of plasma cells ${ }^{12,13}$. The origin of the SCAP from either eccrine or apocrine structures has been supported in the literature. It is probable that SCAP arises from undifferentiated cells with the potential to exhibit both apocrine and eccrine modes of epithelial secretion. Most lesions of SCAP appear to be nearly of apocrine origin, but some exhibit eccrine derivation ${ }^{13}$.

A TAA is also an uncommon sweat gland tumor. TAAs are usually found in middle-aged adults as solitary nodules situated mostly on the scalp. TAAs have numerous, irregular-shaped tubular structures that are usually lined by two layers of epithelial cells. The peripheral layer consists of cuboidal or flattened cells, and the luminal layer is composed of columnar cells ${ }^{13}$. The tubules are embedded in a paucicellular fibrous stroma ${ }^{11-13}$. In our case, the superficial portion of the tumor showed typical SCAP characteristics and the lower portion was representative of a TAA.

The association of TAAs with SCAPs was first described by Toribio et al. $^{3}$ in 1987. Another nine cases of SCAPs combined with TAAs have been reported in the English literature $^{2-10}$ (Table 1). In these cases, SCAPs were also overlaid on TAAs, as in our case. The lesions of SCAPs vary in morphologic character from smooth and flat to raised and verrucous. They also may present as solitary nodules or plaques, or multiple linear papules ${ }^{14,15}$. Ten cases of SCAPs combined with TAAs showed a wide variety of surface appearances; the various morphologic characteristics could be associated with a superficial portion of the SCAP.

SCAPs have been found in $8 \sim 19 \%$ of the lesions of sebaceous nevi, and are one of the most commonly associated appendage tumors of sebaceous nevi ${ }^{13}$. Six of 10 cases of TAAs associated with SCAPs showed pre-existing sebaceous nevi ${ }^{1-6}$. Three of 10 cases did not mention sebaceous nevi ${ }^{8-10}$. In the 3 cases, there might have been no evidence of sebaceous nevi. Only one case of a TAA with a SCAP in the external auditory canal has been reported with no background of sebaceous nevi ${ }^{9}$. In our case, the lower portion of the lesion with a tubular structure may have been ectopic apocrine glands in an underdeveloped sebaceous nevus because our patient was pre-pubertal. Nevertheless, we concluded that our case was a SCAP combined with a TAA because there was no evidence of a pre-existing sebaceous nevus in the completely excised specimen. The intradermal tubular component may be a part of $\mathrm{SCAP}^{16}$. However, the tubular structures in our case were numerous and consisted of compactly gathered forming islands, and so were characteristic of TAA. Also, our case presented on the back, which is a rare site for a sebaceous nevus to develop ${ }^{17}$. The present case is the first report of a SCAP accompanied with a TAA on the back without a sebaceous nevus before puberty.

TAAs and SCAPs may exhibit histopathologic overlap. Kazakov et al. ${ }^{13}$ conducted an interobserver study for a histopathologic reappraisal of tubular adenomas (TAs) and SCAPs with four dermatopathologists. The study confirmed a morphologic overlap between TAs and SCAPs

Table 1. Review of the cases of SCAP combined with TAA

\begin{tabular}{|c|c|c|c|c|c|}
\hline Reference & Age/Sex & Location & Clinical features & Size & Nevus sebaceous \\
\hline Toribio et al. $(1987)^{3}$ & $33 / \mathrm{M}$ & Scalp & An exudative, round, pediculated lesion & $2 \mathrm{~cm}$ & Unmentioned \\
\hline Ansai et al. (1989) ${ }^{4}$ & $22 / \mathrm{M}$ & Scalp & $\begin{array}{l}\text { A pedunculated tumor with lobulated } \\
\text { and erosive surface }\end{array}$ & $1.3 \times 1.6 \times 1 \mathrm{~cm}$ & Unmentioned \\
\hline Epstein et al. $(1990)^{5}$ & $15 / M$ & Chest & Linear grouped shiny erythematous papules & $5 \times 1 \mathrm{~cm}$ & Unmentioned \\
\hline Ishiko et al. (1993) ${ }^{6}$ & $75 / \mathrm{M}$ & Scalp & $\begin{array}{l}\text { A verrucous tumor located on the depigmented } \\
\text { plaque }\end{array}$ & $1.1 \mathrm{~cm}$ & Present \\
\hline Aktepe et al. $(2003)^{7}$ & $19 / M$ & Scalp & A pinkish, hairless and verrucous plaque & $3 \times 1 \mathrm{~cm}$ & Present \\
\hline Ahn et al. $(2004)^{8}$ & $52 / \mathrm{M}$ & Scalp & A dome-shaped nodule & $1.5 \mathrm{~cm}$ & Present \\
\hline Lee et al. $(2005)^{9}$ & $74 / F$ & $\begin{array}{l}\text { External } \\
\text { auditory canal }\end{array}$ & An indurated tumor with central ulceration & $1.5 \times 1 \mathrm{~cm}$ & Absent \\
\hline Yamane et al. $(2007)^{10}$ & $77 / F$ & Breast & $\begin{array}{l}\text { Linearly arranged plaques, an ulcerated } \\
\text { intracutaneous nodule and a red pedunculated } \\
\text { nodule forming gently curved lesion }\end{array}$ & $10 \times 4 \mathrm{~cm}$ & Present \\
\hline Vazmitel et al. (2008) ${ }^{11}$ & $61 / M$ & Scalp & An ulcerated plaque & Unmentioned & Present \\
\hline Kim et al. $(2010)^{12}$ & $40 / F$ & Scalp & A pedunculated nodule & $2.5 \mathrm{~cm}$ & Present \\
\hline Present case (2010) & $12 / F$ & Lower back & An erosive and crusted papillomatous plaque & $1.8 \times 2.5 \mathrm{~cm}$ & Absent \\
\hline
\end{tabular}

SCAP: syringocystadenoma papilliferum, TAA: tubular apocrine adenoma, M: male, F: female. 
and demonstrated a lack of universally accepted diagnostic criteria to classify the lesions with morphologic overlap between TAs and SCAPs, even among experienced dermatopathologists and pathologists.

Ishiko et al. ${ }^{6}$ reviewed 19 cases of TAAs described in the literature. In 10 of the 19 TAA cases, the tumor was connected to the overlying epidermis and it was necessary to differentiate the lesion from a SCAP. They described TAAs as being different from SCAPs in several aspects: 1) TAAs show no cystically-dilated apocrine invaginations extending down from the epidermis; 2) papillary projections are absent; and 3) infiltration of plasma cells is rare or absent.

The term tubulopapillary hidradenoma (TPH) was first proposed by Falck and Jordaan ${ }^{18}$ in 1986, and is a recently proposed category of adnexal tumors that remains controversial. A TPH encompasses a spectrum of lesions from papillary eccrine adenomas (PEAs) to TAAs. This designation indicates a variable degree of differentiation from both apocrine and eccrine glands and it is difficult to precisely distinguish between these types of tumors. A TPH is also closely related to a SCAP. Even though this classification is controversial, it has been proposed that PEAs, TAAs, and SCAPs are an inter-related group of appendage tumors ${ }^{13,19}$. Recent studies have suggested that these tumors arise from either pleuripotential appendage cells or apo-eccrine glands ${ }^{5}$.

In summary, we present a case of a SCAP on the lower back that was histopathologically associated with a TAA without a sebaceous nevus. Despite the rare occurrence, this entity can be considered when similar skin lesions are observed.

\section{REFERENCES}

1. Taylor RS, Perone JB, Kaddu S, Kerl H. Appendage tumors and hamartomas of the skin. In: Wolff K, Goldsmith LA, Katz SI, Gilchrest BA, Paller AS, Leffell DJ, editors. Fitzpatrick's dermatology in general medicine. 7th ed. New York: McGraw Hill, 2008:1068-1087.

2. Ahmed TS, Priore JD, Seykora JT. Tumors of the epidermal appendages. In: Elder DE, Elenitsas R, Johnson BL, Murphy GF, Xu X, editors. Lever's histopathology of the skin. 10th ed. Philadelphia: Lippincott Williams \& Wilkins, 2008:858860.

3. Toribio J, Zulaica A, Peteiro C. Tubular apocrine adenoma. J Cutan Pathol 1987;14:114-117.

4. Ansai S, Watanabe S, Aso K. A case of tubular apocrine adenoma with syringocystadenoma papilliferum. J Cutan Pathol 1989;16:230-236.

5. Epstein BA, Argenyi ZB, Goldstein G, Whitaker D. An unusual presentation of a congenital benign apocrine hamartoma. J Cutan Pathol 1990; 17:53-58.

6. Ishiko A, Shimizu H, Inamoto N, Nakmura K. Is tubular apocrine adenoma a distinct clinical entity? Am J Dermatopathol 1993;15:482-487.

7. Aktepe F, Demir Y, Dilek FH. Tubular apocrine adenoma in association with syringocystadenoma papilliferum. Dermatol Online J 2003;9:7.

8. Ahn BK, Park YK, Kim YC. A case of tubular apocrine adenoma with syringocystadenoma papilliferum arising in nevus sebaceus. J Dermatol 2004;31:508-510.

9. Lee CK, Jang KT, Cho YS. Tubular apocrine adenoma with syringocystadenoma papilliferum arising from the external auditory canal. J Laryngol Otol 2005;119:1004-1006.

10. Yamane N, Kato N, Yanagi T, Osawa R. Naevus sebaceus on the female breast accompanied with a tubular apocrine adenoma and a syringocystadenoma papilliferum. $\mathrm{Br} \mathrm{J}$ Dermatol 2007;156:1397-1399.

11. Vazmitel M, Michal M, Mukensnabl P, Kazakov DV. Syringocystadenoma papilliferum with sebaceous differentiation in an intradermal tubular apocrine component. Report of a case. Am J Dermatopathol 2008;30:51-53.

12. Kim MS, Lee JH, Lee WM, Son SJ. A case of tubular apocrine adenoma with syringocystadenoma papilliferum that developed in a nevus sebaceus. Ann Dermatol 2010;22: 319-322.

13. Kazakov DV, Bisceglia M, Calonje E, Hantschke M, Kutzner $H$, Mentzel T, et al. Tubular adenoma and syringocystadenoma papilliferum: a reappraisal of their relationship. An interobserver study of a series, by a panel of dermatopathologists. Am J Dermatopathol 2007;29:256-263.

14. Townsend TC, Bowen AR, Nobuhara KK. Syringocystadenoma papilliferum: an unusual cutaneous lesion in a pediatric patient. J Pediatr 2004; 145:131-133.

15. Hann SK, Choi YS, Choi EH. Syringocystadenoma papilliferum. Ann Dermatol 1990;2:100-104.

16. Requena L, Kiryu $H$, Ackerman AB. Neoplasms with apocrine differentiation. Philadelphia, PA: Lippicott-Raven, 1998.

17. James WD, Berger TG, Elston DM. Epidermal nevi, neoplasms, and cysts. In: Andrews' diseases of the skin clinical dermatology. 10th ed. Philadelphia: Elsevier, 2006: 633-683.

18. Falck VG, Jordaan HF. Papillary eccrine adenoma. A tubulopapillary hidradenoma with eccrine differentiation. Am J Dermatopathol 1986;8:64-72.

19. Hsu PJ, Liu CH, Huang CJ. Mixed tubulopapillary hidradenoma and syringocystadenoma papilliferum occurring as a verrucous tumor. J Cutan Pathol 2003;30:206-210. 